\title{
HERANÇA DE CARACTERES DO TRIGO RELACIONADOS À QUALIDADE DE PANIFICAÇÃO'
}

\author{
ANDRÉA MITTELMANN² , JOSÉ FERNANDES BARBOSA NETO³ , FERNANDO IRAJÁ FÉLIX DE CARVALHO4, \\ MARIA CÉLIA IBAÑES LEMOS ${ }^{5}$, LÉO DUC HAA DA CONCEIÇÃO ${ }^{6}$
}

\begin{abstract}
RESUMO - A qualidade de panificação possui grande importância para a indústria e produtores de trigo, e possibilita a agregação de valor de mercado ao produto. $\mathrm{O}$ melhoramento voltado para a qualidade, porém, tem sido dificultado pela complexidade do caráter e pela necessidade de testes adequados para a seleção em gerações segregantes. O objetivo deste trabalho foi analisar a herança dos caracteres volume de sedimentação, índice de sedimentação e teor de proteína, em dez cruzamentos envolvendo cinco cultivares de trigo classificadas distintamente quanto à qualidade de panificação. As médias dos genitores diferiram entre si em relação a todos os caracteres. Através das variâncias e dos parâmetros genéticos estimados, foi detectada variabilidade nos cruzamentos, no tocante aos caracteres avaliados, o que sugere a existência de genes complementares relativos a esses caracteres. A cultivar CEP 24Industrial contribuiu com o maior número de genes para o incremento da qualidade no conjunto de cruzamentos analisados, e possui alelos favoráveis também para o teor de proteína. Os caracteres volume e índice de sedimentação foram fortemente associados e apresentaram herdabilidade semelhante. O teor de proteínas influenciou as medidas de qualidade obtidas pelo teste de sedimentação.
\end{abstract}

Termos para indexação: cereais, proteína, qualidade industrial, teste de sedimentação.

\section{INHERITANCE OF WHEAT TRAITS RELATED TO BREAD-MAKING QUALITY}

\begin{abstract}
Bread-making quality is important to the industry and farmers. It improves market value of wheat. Breeding for quality has been difficult because it is a very complex trait affected by genetic and environmental factors. In addition, it requires specific tests for early-generation selection. The objective of this study was to analyse the inheritance of sedimentation volume, sedimentation index and protein content in ten crosses between five cultivars with different bread-making quality. Parental means for sedimentation volume and index and protein content differed from each other. Variability for all traits was detected in the crosses by variances and genetic parameters and the occurrence of complementary genes may be suggested. The cultivar CEP 24-Industrial contributed with the highest number of genes for quality improvement. It also had favorable genes for protein content. The traits sedimentation volume and sedimentation index were strongly associated, and had similar heritability. Protein content affected quality estimates obtained from the sedimentation test.
\end{abstract}

Index terms: cereals, protein, industrial quality, sedimentation test.

\footnotetext{
${ }^{1}$ Aceito para publicação em 24 de maio de 1999.

${ }^{2}$ Eng. Agrôn., M.Sc., Universidade Federal do Rio Grande do Sul (UFRGS), Av. Bento Gonçalves, 7712, Caixa Postal 776, CEP 91501-970 Porto Alegre, RS. E-mail: amittelm@ciagri.usp.br

${ }^{3}$ Eng. Agrôn., Ph.D., Dep. de Plantas de Lavoura, Faculdade de Agronomia, UFRGS. Bolsista do CNPq. E-mail: jfbn@vortex.ufrgs.br

${ }^{4}$ Eng. Agrôn., Ph.D., Dep. de Fitotecnia, Universidade Federal de Pelotas, Campus Universitário, Caixa Postal 354, CEP 96001-970 Pelotas, RS.

${ }^{5}$ Eng. Agrôn., M.Sc., Polimate Importadora e Exportadora de Medidores Ltda, Rua Coronel Lucas de Oliveira, 364, CEP 90440-010 Porto Alegre, RS.

${ }^{6}$ Estudante de Agronomia, UFRGS. Bolsista da FAPERGS.
}

\section{INTRODUÇÃO}

O melhoramento da qualidade representa uma oportunidade de agregar valor de mercado aos produtos agrícolas. No caso do trigo, em face do comércio internacional, existe uma forte interação entre qualidade e preço (Wrigley, 1994). A fabricação de pães em escala comercial é uma das maiores utilizações da farinha de trigo. Portanto, as cultivares desenvolvidas devem ter o potencial de produzir uma farinha que confira ao produto final as características de crescimento, textura, sabor e coloração desejadas e, ainda, que apresente adequação ao processo mecânico de preparo. Entre os caracteres que in- 
fluem marcadamente na qualidade de panificação, encontram-se o teor de proteína (Pomeranz, 1973) e a variação tanto qualitativa, em termos da composição de subunidades, como quantitativa, em relação às diferentes frações protéicas que compõem o glúten, especialmente as gluteninas (Payne et al., 1979; Moonen et al., 1982; Brunori et al., 1989).

A seleção visando à qualidade de panificação vem sendo realizada em diversos programas de melhoramento (Wrigley, 1994); entretanto, a influência do ambiente dificulta a seleção de plantas em gerações segregantes e prejudica a avaliação de linhagens, em virtude da interação genótipo $\mathrm{x}$ ambiente (Blackman \& Payne, 1987). Dificuldade adicional tem sido causada pela necessidade de testes que possam ser feitos com pequenas quantidades de farinha a fim de que possam ser realizados ao longo das gerações segregantes.

Os denominados testes de panificação consistem na fabricação do pão dentro de procedimentos padronizados, que variam de acordo com o tipo de produto a ser obtido (Blackman \& Payne, 1987; Mandarino, 1993). Testes que avaliam a qualidade da farinha através de suas características físicas e capacidade de fermentação são chamados análises tecnológicas. A alveografia, mixografia e farinografia são alguns dos testes reológicos utilizados para estimar a força do glúten. Alguns desses métodos são baseados em critérios empíricos, e por isso sofrem críticas por parte de pesquisadores. Além disso, sua utilização nas fases iniciais do melhoramento é limitada pelas quantidades de farinha exigidas e por sofrerem alta influência do ambiente.

Segundo Blackman \& Payne (1987), para que um teste obtenha sucesso em estimar qualidade de proteína para panificação, deve satisfazer os seguintes requerimentos: ser fácil e simples de realizar, para que várias progênies possam ser analisadas em um dia; necessitar de pequena quantidade de farinha, preferencialmente de, no máximo, 10 a 12 gramas, para que a progênie de cada planta possa ser testada individualmente; ser independente de outros fatores, como conteúdo de proteína e atividade da alfa-amilase, que afetam a qualidade de panificação e que podem variar grandemente com as condições de cultivo. Nesse sentido, pode ser destacado o teste de sedimentação com SDS (dodecil sulfato de sódio), que utiliza apenas um grama de farinha. Esse teste está baseado na insolubilidade em meio ácido das proteínas que formam o glúten e proporciona uma estimativa da força de glúten através do volume do sedimento medido. Moonen et al. (1982), utilizando 60 cultivares de trigo, encontraram uma alta correlação $(r=0,82)$ entre o teste de sedimentação com SDS e o volume obtido em testes de panificação. Em três cruzamentos envolvendo cultivares de trigo duro (Triticum turgidum L. var. durum) com forças de glúten contrastantes, foram obtidos valores de herdabilidade moderados no tocante aos valores de índice de sedimentação, de 0,57, 0,67 e 0,68 (Clarke et al., 1993). Por outro lado, Lorenzo \& Kronstad (1987) observaram que os valores do volume de sedimentação eram altamente influenciados pela variação na concentração de proteína, o que dificulta a interpretação dos resultados. Dexter et al. (1980) recomendaram a associação das informações de teor de proteína e volume de sedimentação a fim de melhor explicar a variação em qualidade.

Este trabalho teve por objetivos analisar a herança dos caracteres volume de sedimentação, índice de sedimentação e teor de proteína em trigo, estimar as correlações genéticas entre eles, e identificar cultivares de interesse para uso no melhoramento desses caracteres.

\section{MATERIAL E MÉTODOS}

Os experimentos foram conduzidos nos anos de $1995 \mathrm{e}$ 1996, na Estação Experimental Agronômica da Universidade Federal do Rio Grande do Sul (EEA/UFRGS), e no telado e laboratórios do Departamento Plantas de Lavoura, na Faculdade de Agronomia.

Foram utilizadas como genitores cinco cultivares de trigo recomendadas para o Estado do Rio Grande do Sul (Reunião ..., 1996) (Tabela 1), representando três grupos de classificação quanto à qualidade industrial, de acordo com a legislação brasileira, sendo duas cultivares classificadas como superiores, uma, intermediária, e duas, da classe comum.

\section{Obtenção das gerações segregantes}

No inverno de 1995, as cinco cultivares foram cruzadas entre si na forma de um dialélico, sem haver distinção entre os cruzamentos recíprocos, resultando em dez cruzamentos. As cultivares foram semeadas em bloco de cruzamen- 
tos, em parcelas compostas por quatro linhas de $3 \mathrm{~m}$ de comprimento, com espaçamento de $0,3 \mathrm{~m}$ entre linhas e entre plantas dentro da linha. Por meio de cruzamentos artificiais, foram obtidas as sementes $F_{1}$, tendo sido emasculadas e polinizadas pelo menos dez espigas por cruzamento. Parte das sementes $F_{1}$ produzidas (20 sementes por cruzamento) foram semeadas no verão de 1995/1996, em telado, na Faculdade de Agronomia, para a obtenção das sementes $F_{2}$.

\section{Desenvolvimento do experimento a campo}

No inverno de 1996 foram semeadas no campo as quatro gerações envolvidas neste estudo: $\mathrm{P}_{1}, \mathrm{P}_{2}, \mathrm{~F}_{1}$ e $\mathrm{F}_{2}$. O delineamento experimental foi em blocos casualizados. Em cada cruzamento foram semeadas duas repetições, compostas de quatro linhas de cada um dos genitores, quatro a 12 linhas de plantas $\mathrm{F}_{2}$, de acordo com o número de sementes disponível, e, apenas na primeira repetição, duas a quatro linhas de plantas $F_{1}$. O cruzamento CEP 24-Industrial x Trigo BR 23 foi excluído, pelo número insuficiente de sementes. O comprimento das linhas e o espaçamento utilizado foram semelhantes aos descritos para 1995. Ao final do ciclo, todas as plantas foram colhidas de forma individual e debulhadas mecanicamente para que os grãos fossem submetidos às análises de qualidade.

\section{Avaliações}

As avaliações foram realizadas utilizando as sementes colhidas no ano de 1996, envolvendo as gerações $\mathrm{P}_{1}, \mathrm{P}_{2}, \mathrm{~F}_{1}$ e $F_{2}$. Todas as avaliações foram realizadas tendo como unidade experimental a planta.

Amostras de $1 \mathrm{~g}$ de farinha integral obtida em moinho "Falling Number A/B" com granulometria de 0,5 mm foram utilizadas na determinação do volume de sedimentação na presença de SDS - dodecil sulfato de sódio -, de acordo com o método descrito por Peña \& Amaya (1985). As análises foram realizadas no Laboratório de Qualidade de Trigo da Embrapa-Centro Nacional de Pesquisa de

TABELA 1. Classificação comercial das cultivares utilizadas como genitores.

\begin{tabular}{ll}
\hline Cultivar & Classificação comercial \\
\hline Trigo BR 23 & Comum \\
Trigo BR 32 & Intermediária \\
CEP 24-Industrial & Superior \\
EMBRAPA 16 & Superior \\
EMBRAPA 24 & Comum \\
\hline
\end{tabular}

Trigo. O valor medido visualmente, em provetas de $25 \mathrm{~mL}$, correspondeu ao volume de sedimentação. O índice de sedimentação foi obtido pela divisão do volume de sedimentação pelo teor de proteína, para cada amostra.

O conteúdo total de proteína na farinha foi obtido por análise de refletância no infravermelho proximal (NIR). Todas as amostras, constituídas por grãos inteiros, foram lidas em um aparelho NR 5000 para os comprimentos de onda de 1.100 a $2.500 \mathrm{~nm}$, região do infravermelho proximal. O programa utilizado para a obtenção das curvas de leitura, seleção das amostras para calibração, calibração e processamento dos dados foi o New Infrasoft International Software - NIRS 3 (NEWISI) (Infrasoft International, 1995). Para a calibração do aparelho foram selecionadas 60 amostras, aproximadamente 5\% do total de amostras, que foram moídas e analisadas em laboratório. $\mathrm{O}$ método empregado para medir o conteúdo de proteína foi o micro-Kjeldahl. O teor de $\mathrm{N}$ obtido foi multiplicado por 5,7 , que corresponde ao fator de conversão para proteína em trigo. O método empregado para a calibração foi o de regressão por meio dos componentes principais. As equações de regressão para teor de proteína foram aplicadas aos valores de refletância, resultando em estimativas que foram tomadas como os valores individuais das amostras no presente estudo.

A diferença entre as cinco cultivares parentais, relativa a cada uma das características, foi testada pelo teste de Tukey de comparação múltipla de médias, após a análise de variância. A herdabilidade no sentido amplo foi estimada com base na decomposição da variância fenotípica, segundo o método descrito por Allard (1960). As variâncias genéticas foram testadas pelo teste $\mathrm{t}$ a $5 \%$ de probabilidade.

Os parâmetros genéticos [m] (constante dependente da ação dos genes não considerados na análise e da ação de causas não genéticas), [a] (aditividade) e [d] (dominância) foram estimados quanto a cada cruzamento e característica, mediante análise de média de gerações para um modelo de três parâmetros, utilizando o método dos quadrados mínimos ponderados (Mather \& Jinks, 1982). A estimação dos parâmetros foi seguida de teste de escala conjunto, comparando as médias observadas com as esperadas pelo teste do qui-quadrado $\left(\chi^{2}\right)$.

Também foram estudadas as correlações genéticas entre todas as características medidas. Essas análises foram realizadas com base nas variâncias e covariâncias genéticas (Allard, 1960), através da seguinte equação:

$$
r_{g}=\frac{\operatorname{covg}(x y)}{\sqrt{\left(\sigma_{g x}^{2} \cdot \sigma_{g y}^{2}\right)}}
$$

onde x e y são as características em estudo, $\sigma_{\mathrm{g}}^{2}$ representa a estimativa da variância genética, e covg é a estimativa da covariância genética. 


\section{RESULTADOS E DISCUSSÃO}

Mediante a análise de variância, foi verificada a existência de diferenças entre os genótipos parentais para as características em estudo (Tabela 2). Para o caráter volume de sedimentação, as cultivares com maior média foram CEP 24-Industrial e Trigo BR 23. As cultivares EMBRAPA 16, EMBRAPA 24 e Trigo BR 32 não diferiram significativamente entre si nem em relação à Trigo BR 23 , mas podem ser incluídas em um grupo inferior, pela diferença em relação à CEP 24-Industrial. As médias dos genitores relativas a volume de sedimentação ficaram, segundo classificação proposta na literatura (Williams et al., 1988 citados por Guarienti, 1996), nas classes denominadas "média força fraco" na cultivar Trigo BR 32 , "média força forte" nas cultivares Trigo BR 23 , EMBRAPA 16 e EMBRAPA 24 e "muito forte", na CEP 24-Industrial.

Também quanto ao índice de sedimentação (Tabela 2), três grupos foram estabelecidos, aparecendo a cultivar CEP 24-Industrial com a maior média, e Trigo BR 32 , com a mais baixa. A cultivar CEP 24-Industrial, que foi superior às demais quanto ao volume e índice de sedimentação, é classificada como "superior" quanto à qualidade, conforme a legislação brasileira. Por outro lado, os genótipos Trigo BR 32 e EMBRAPA 16, apesar de classificados como "intermediário" e "superior", respectivamente, ficaram no grupo de baixo volume de sedimentação, sendo Trigo BR 32 inferior aos demais genitores também quanto ao índice de sedimentação.

As médias dos genitores quanto ao teor de proteína variaram entre as classes "alta" - EMBRAPA 16 e EMBRAPA 24 - a "muito alta" - Trigo BR 23, Trigo BR 32 e CEP 24-Industrial -, de acordo com a literatura consultada (Williams et al., 1988 citado por Guarienti, 1996). Esses dados, em conjunto com os de volume de sedimentação, sugerem que as condições do ambiente foram favoráveis ao desenvolvimento da cultura e aos aspectos relacionados à qualidade. A cultivar Trigo BR 32 teve destaque, seguida das cultivares CEP 24-Industrial, Trigo BR 23 e EMBRAPA 24 (Tabela 2). É possível que essa capacidade de a cultivar Trigo BR 32 acumular altos teores de proteína seja responsável por sua inclusão como "intermediária”, interferindo positivamente nos resultados das denominadas análises tecnológicas, que incluem a farinografia, alveografia e índice de queda, principais testes utilizados para classificar as cultivares no momento da recomendação. Além disso, é importante considerar que a classificação adotada no momento da recomendação de uma cultivar utiliza resultados de ensaios desenvolvidos em vários locais e anos, e este trabalho apresenta informações referentes apenas ao ano de 1996 e a um local de cultivo.

A análise da geração $F_{2}$ permitiu detectar variabilidade genética dos caracteres avaliados em diferentes cruzamentos. As variâncias genéticas foram significativamente diferentes de zero nos cruzamentos Trigo BR 23 x Trigo BR 32 , EMBRAPA 16 x Trigo BR 32, EMBRAPA 24 x Trigo BR 23 e EMBRAPA $24 \times$ EMBRAPA 16 quanto ao volume de sedimentação, e nos cruzamentos Trigo BR 23 x Trigo BR 32, CEP 24-Industrial x EMBRAPA 24, EMBRAPA 16 x Trigo BR 32 e EMBRAPA 24 X Trigo BR 23, quanto ao índice de sedimentação. Quanto ao teor de proteína, apenas no cruzamento Trigo BR 32 x EMBRAPA 24 houve significância do teste $\mathrm{t}$ com relação às variâncias genéticas (Tabela 3).

TABELA 2. Médias de cinco cultivares de trigo referentes aos caracteres volume de sedimentação $(\mathrm{mL})$, índice de sedimentação e teor de proteína (\%). EEA/UFRGS, 19961.

\begin{tabular}{lccc}
\hline Cultivar & Volume de sedimentação & Índice de sedimentação & Teor de proteína \\
\hline CEP 24-Industrial & $17,71 \mathrm{a}$ & $1,26 \mathrm{a}$ & $14,22 \mathrm{ab}$ \\
Trigo BR 23 & $14,42 \mathrm{ab}$ & $1,04 \mathrm{ab}$ & $13,82 \mathrm{ab}$ \\
EMBRAPA 16 & $13,16 \mathrm{~b}$ & $1,10 \mathrm{ab}$ & $12,07 \mathrm{~b}$ \\
EMBRAPA 24 & $12,95 \mathrm{~b}$ & $0,97 \mathrm{ab}$ & $13,33 \mathrm{ab}$ \\
Trigo BR 32 & $11,85 \mathrm{~b}$ & $0,79 \mathrm{~b}$ & $15,15 \mathrm{a}$ \\
\hline
\end{tabular}

${ }^{1}$ Médias seguidas da mesma letra não diferem significativamente pelo teste de Tukey a $5 \%$ de probabilidade. 
A magnitude das variâncias não foi consistente com a diferença dos pais, com base nos grupos formados através do teste de médias. As maiores variâncias não pertenceram aos cruzamentos entre genitores mais contrastantes, e em vários casos foi observada segregação transgressiva, o que sugere a ação de genes complementares. Da mesma forma, a magnitude das variâncias não foi explicada consistentemente pela classificação comercial das cultivares; isto evidencia a complexidade da herança e a provável ação de outros componentes não avaliados neste trabalho.

A decomposição da variância fenotípica em variância genética e de ambiente (Allard, 1960) mostrou, quanto ao teor de proteína e ao volume de sedimentação, a predominância dos efeitos de ambiente. $\mathrm{O}$ mesmo ocorreu no tocante ao índice de sedimentação. Esses resultados não são condizentes com os apresentados por Dexter et al. (1980) que, tendo observado que as medidas de volume de sedimentação eram influenciadas pela concentração de proteína na farinha, recomendaram a associação das informações de teor de proteína e volume de sedimentação para obter melhores estimativas da qualidade de panificação. Um aspecto que deve ser destacado é que no cruzamento Trigo BR $23 \mathrm{x}$ EMBRAPA 24, em que os genitores possuíam igual classificação - no tipo "comum" -, a variância genética representou parte importante da variância fenotípica total quanto ao volume e ao índice de sedimentação, levando a valores moderados de herdabilidade. Como, no que diz respeito a esse cruzamento, o índice de sedimentação não pareceu sofrer influência significativa do teor de proteína, é possível sugerir novamente a ação de genes complementares e de outros componentes genéticos não avaliados. O cruzamento EMBRAPA 16 $x$ CEP 24-Industrial obteve a segunda menor herdabilidade no índice de sedimentação. As duas cultivares pertencem à mesma classe, conforme a classificação comercial (Reunião..., 1996), podendo tal similaridade explicar em parte a pouca variabilidade genética promovida pelo cruzamento. Por outro lado, a classificação comercial não foi suficiente para explicar a variabilidade existente nos demais cruzamentos.

As estimativas dos parâmetros genéticos [m], [a] e [d], bem como do grau de dominância (d/a), evidenciaram a existência de uma ampla variação entre cruzamentos quanto ao controle genético das características estudadas, embora em nenhum dos casos o teste de escala tenha indicado que os efeitos epistáticos, não incluídos no modelo, deveriam ser considerados. Não foi possível realizar o teste nos cruzamentos CEP 24-Industrial x EMBRAPA 24 e EMBRAPA 24 x EMBRAPA 16, em relação a todos os caracteres, por não haver suficientes graus de liberdade. O mesmo ocorreu com o cruzamento Trigo BR 23 x EMBRAPA 16 quanto ao teor de proteína.

TABELA 3. Variâncias de ambiente (VE) e variância genética (VG) dos caracteres volume de sedimentação (VS), índice de sedimentação (IS) e teor de proteína (P) em nove cruzamentos de trigo. EEA/UFRGS, 1996.

\begin{tabular}{|c|c|c|c|c|c|c|}
\hline \multirow[t]{2}{*}{ Cruzamentos } & \multicolumn{2}{|c|}{ VS } & \multicolumn{2}{|c|}{ IS } & \multicolumn{2}{|c|}{$\mathrm{P}$} \\
\hline & VE & VG & VE & VG & VE & VG \\
\hline Trigo BR $23 \times$ Trigo BR 32 & 3,02 & $2,68^{*}$ & 0,014 & $0,020^{*}$ & 1,41 & 0,35 \\
\hline Trigo BR 23 x EMBRAPA 16 & - & - & - & - & 0,92 & 0,38 \\
\hline Trigo BR 32 x CEP 24-Industrial & 4,06 & 2,49 & 0,009 & 0,012 & 2,50 & 0,19 \\
\hline Trigo BR 32 x EMBRAPA 24 & 3,55 & 0,13 & 0,018 & 0,000 & 0,88 & $0,94 *$ \\
\hline CEP 24-Industrial x EMBRAPA 24 & 4,70 & 1,34 & 0,014 & $0,024^{*}$ & 1,69 & 0,74 \\
\hline EMBRAPA 16x Trigo BR 32 & 2,61 & $8,34 *$ & 0,018 & $0,050^{*}$ & 1,04 & 0,49 \\
\hline EMBRAPA 16 x CEP 24-Industrial & 3,56 & 3,14 & 0,016 & 0,006 & 1,89 & 0,54 \\
\hline EMBRAPA 24 x Trigo BR 23 & 2,11 & $1,89 *$ & 0,011 & $0,044 *$ & 0,65 & 0,23 \\
\hline EMBRAPA 24 x EMBRAPA 16 & 2,18 & $5,53 *$ & 0,018 & 0,021 & 0,74 & 0,58 \\
\hline
\end{tabular}

* Variâncias genéticas significativas pelo teste t a $5 \%$ de probabilidade. 
No que se refere ao volume de sedimentação, as estimativas do parâmetro [a] foram significativas na maioria dos cruzamentos, exceto EMBRAPA $16 \mathrm{x}$ Trigo BR 32, EMBRAPA 24 x Trigo BR 23 e EMBRAPA $24 \times$ EMBRAPA 16. As estimativas do parâmetro [d] somente não foram significativas em dois dos cruzamentos: EMBRAPA 24 x Trigo BR 23 e EMBRAPA 24 x EMBRAPA 16. A magnitude dos efeitos de dominância em relação aos de aditividade, nesses cruzamentos, variou de $-2,33$ a 1,36 (Tabela 4).

O caráter índice de sedimentação apresentou estimativas significativas quanto aos três parâmetros genéticos, com exceção das estimativas de [d] nos cruzamentos Trigo BR 32 x CEP 24-Industrial, EMBRAPA 16 x CEP 24-Industrial, EMBRAPA $24 \mathrm{x}$ Trigo BR 23 e EMBRAPA 24 x EMBRAPA 16 e a estimativa de [a] no cruzamento EMBRAPA $24 \times$ Trigo BR 23. As estimativas do grau de dominância foram de 0,20 a 2,07 (Tabela 5).

Em relação ao teor de proteína, três dos cruzamentos estudados não apresentaram estimativas significativamente diferentes de zero quanto ao parâmetro relacionado à aditividade: Trigo BR 23 x Trigo BR 32, Trigo BR 32 x CEP 24-Industrial e EMBRAPA 24 x Trigo BR 23. O parâmetro [d] foi significativo na maioria dos cruzamentos, com exceção de Trigo BR 23 x EMBRAPA 16, Trigo BR 32 x CEP 24-Industrial e CEP 24-Industrial x EMBRAPA 24. O grau de dominância quanto a essa característica variou entre os cruzamentos de -1,34 a 3,63 (Tabela 6).
Além do desempenho per se de um genitor, a informação sobre sua contribuição para o progresso genético em diferentes cruzamentos é de grande interesse em programas de melhoramento (Falconer, 1989). As estimativas de [a] com relação ao volume de sedimentação indicaram que a cultivar CEP 24-Industrial contribuiu com maior número de genes de efeito aditivo para o incremento do caráter. As cultivares Trigo BR 32 e EMBRAPA 24 contribuíram para a redução do caráter, no conjunto de cruzamentos analisados, e as cultivares Trigo BR 23 e EMBRAPA 16 ocuparam posição intermediária. Quanto ao caráter índice de sedimentação, as contribuições dos genitores ocorreram de forma semelhante à do volume de sedimentação. Em relação ao teor de proteína, a cultivar Trigo BR 32 apresentou maior número de genes para o incremento do caráter, assim como a cultivar CEP 24-Industrial. As cultivares EMBRAPA 24 e EMBRAPA 16 apresentaram maior número de genes para a redução do caráter. Tais observações foram coerentes com as diferenças entre as médias dos genitores. O grau de dominância foi superior à unidade em muitos casos, o que indica que os efeitos de dominância possuem importância em relação aos três caracteres estudados.

Em vários dos cruzamentos analisados, as estimativas de [a] e [d] foram significativas, embora o teste $\mathrm{t}$ tenha evidenciado a não-significância das variâncias genéticas. Os dois testes utilizam diferentes informações e devem ser interpretados de maneira complementar. Neste trabalho, o número de indiví-

TABELA 4. Valores estimados dos parâmetros [m], [a] e [d], grau de dominância (d/a) e significância do teste de escala para o caráter volume de sedimentação, em nove cruzamentos de trigo. EEA/UFRGS, 1996.

\begin{tabular}{lccccc}
\hline Cruzamento & {$[\mathrm{m}]$} & {$[\mathrm{a}]$} & {$[\mathrm{d}]$} & $\chi^{2}$ & $\mathrm{~d} / \mathrm{a}$ \\
\hline Trigo BR 23 x Trigo BR 32 & $13,79 \pm 0,23$ & $1,51 \pm 0,23$ & $1,16 \pm 0,53$ & $\mathrm{~ns}$ & 0,77 \\
Trigo BR 23 x EMBRAPA 16 & - & - & - & - & - \\
Trigo BR 32 x CEP 24-Industrial & $15,37 \pm 0,38$ & $-3,46 \pm 0,39$ & $-0,25 \pm 0,68$ & $\mathrm{~ns}$ & - \\
Trigo BR 32 x EMBRAPA 24 & $12,12 \pm 0,14$ & $-0,64 \pm 0,14$ & $1,49 \pm 0,45$ & $\mathrm{~ns}$ & $-2,33$ \\
CEP 24-Industrial x EMBRAPA 24 & $15,04 \pm 0,24$ & $2,51 \pm 0,24$ & $3,41 \pm 0,82$ & 1 & 1,36 \\
EMBRAPA 16x Trigo BR 32 & $12,40 \pm 0,20$ & $0,33 \pm 0,21$ & $1,65 \pm 0,43$ & $\mathrm{~ns}$ & - \\
EMBRAPA 16 x CEP 24-Industrial & $15,26 \pm 0,25$ & $-1,82 \pm 0,26$ & $0,86 \pm 0,44$ & $\mathrm{~ns}$ & $-0,47$ \\
EMBRAPA 24 x Trigo BR 23 & $13,67 \pm 0,17$ & $-0,26 \pm 0,17$ & $0,10 \pm 0,33$ & $\mathrm{~ns}$ & - \\
EMBRAPA 24 x EMBRAPA 16 & $13,42 \pm 0,21$ & $-0,20 \pm 0,21$ & $0,72 \pm 1,45$ & 1 & - \\
\hline
\end{tabular}

${ }^{1}$ Não há graus de liberdade para o teste. 
duos nas gerações $F_{1}$ e $F_{2}$ foi reduzido em muitos dos cruzamentos, tornando o teste das variâncias bastante rígido.

Os valores de herdabilidade quanto ao volume de sedimentação variaram de 0,04 a 0,76, ficando a herdabilidade média em 0,44 (Tabela 7). Os maiores valores pertenceram aos cruzamentos EMBRAPA 16 x Trigo BR 32 e EMBRAPA 24 x EMBRAPA 16. A herdabilidade média quanto ao índice de sedimentação foi de 0,47 , e variou entre os cruzamentos de -0,10 (zero) a 0,74. Os cruzamentos EMBRAPA 16 $x$ Trigo BR 32, CEP 24-Industrial x EMBRAPA 24, Trigo BR 32 x CEP 24-Industrial e EMBRAPA 24 x EMBRAPA 16 apresentaram herdabilidade acima de 0,50. A herdabilidade do teor de proteína variou de 0,07 a 0,52 , e a média entre cruzamentos foi de 0,29. A herdabilidade mais elevada correspondeu ao cruzamento Trigo BR 32 x EMBRAPA 24 (Tabela 7).
As correlações genéticas entre volume e índice de sedimentação foram significativas em todos os cruzamentos, exceto Trigo BR 32 x EMBRAPA 24, apresentando valores superiores aos das correlações envolvendo outros caracteres. Esses valores oscilaram entre 0,45 e 1,04 (Tabela 8). Correlações significativas entre o volume de sedimentação e o teor de proteína foram obtidas para os cruzamentos Trigo BR 23 x Trigo BR 32 , Trigo BR 32 x EMBRAPA 24, CEP 24-Industrial x EMBRAPA 24, EMBRAPA 16 x Trigo BR 32 e EMBRAPA 16 x CEP 24-Industrial. Em dois cruzamentos, essas correlações foram negativas, e nos demais, positivas (Tabela 8). Entre os caracteres índice de sedimentação e teor de proteína foram observadas correlações significativas nos cruzamentos Trigo BR 23 x Trigo BR 32, Trigo BR 32 x CEP 24-Industrial e CEP 24-Industrial x EMBRAPA 24, as quais foram negativas, variando entre $-0,54$ e $-1,02$ (Tabela 8)

TABELA 5. Valores estimados dos parâmetros [m], [a] e [d], grau de dominância (d/a) e significância do teste de escala para o caráter índice de sedimentação, em nove cruzamentos de trigo. EEA/UFRGS, 1996.

\begin{tabular}{|c|c|c|c|c|c|}
\hline Cruzamento & {$[\mathrm{m}]$} & [a] & [d] & $\chi^{2}$ & $\mathrm{~d} / \mathrm{a}$ \\
\hline Trigo BR 23 x Trigo BR 32 & $0,93 \pm 0,01$ & $0,17 \pm 0,01$ & $0,17 \pm 0,04$ & ns & 1,00 \\
\hline Trigo BR 23 x EMBRAPA 16 & - & - & - & - & - \\
\hline Trigo BR 32 x CEP 24-Industrial & $1,05 \pm 0,02$ & $-0,26 \pm 0,02$ & $-0,05 \pm 0,03$ & ns & - \\
\hline Trigo BR 32 x EMBRAPA 24 & $0,85 \pm 0,01$ & $1,75 \pm 0,01$ & $0,15 \pm 0,03$ & ns & 0,20 \\
\hline CEP 24-Industrial x EMBRAPA 24 & $1,08 \pm 0,01$ & $0,13 \pm 0,01$ & $0,27 \pm 0,06$ & 1 & 2,07 \\
\hline EMBRAPA 16x Trigo BR 32 & $0,94 \pm 0,02$ & $0,12 \pm 0,02$ & $0,18 \pm 0,04$ & ns & 1,50 \\
\hline EMBRAPA 16 x CEP 24-Industrial & $1,19 \pm 0,02$ & $-0,09 \pm 0,02$ & $-0,01 \pm 0,03$ & ns & - \\
\hline EMBRAPA 24 x Trigo BR 23 & $1,02 \pm 0,01$ & $-0,01 \pm 0,01$ & $-0,01 \pm 0,02$ & ns & - \\
\hline EMBRAPA $24 \times$ EMBRAPA 16 & $1,08 \pm 0,02$ & $-0,07 \pm 0,02$ & $-0,12 \pm 0,11$ & 1 & - \\
\hline
\end{tabular}

${ }^{1}$ Não há graus de liberdade para o teste.

TABELA 6. Valores estimados dos parâmetros [m], [a] e [d], grau de dominância (d/a) e significância do teste de escala para o caráter teor de proteína, em nove cruzamentos de trigo. EEA/UFRGS, 1996.

\begin{tabular}{|c|c|c|c|c|c|}
\hline Cruzamento & {$[\mathrm{m}]$} & [a] & [d] & $\chi^{2}$ & $\mathrm{~d} / \mathrm{a}$ \\
\hline Trigo BR 23 x Trigo BR 32 & $14,84 \pm 0,18$ & $-0,36 \pm 0,19$ & $-1,26 \pm 0,31$ & ns & - \\
\hline Trigo BR 23 x EMBRAPA 16 & $13,07 \pm 0,11$ & $0,72 \pm 0,11$ & $0,07 \pm 0,40$ & 1 & - \\
\hline Trigo BR 32 x CEP 24-Industrial & $14,78 \pm 0,24$ & $0,26 \pm 0,25$ & $-0,01 \pm 0,47$ & ns & - \\
\hline Trigo BR 32 x EMBRAPA 24 & $14,50 \pm 0,11$ & $1,00 \pm 0,11$ & $-0,63 \pm 0,22$ & ns & $-0,63$ \\
\hline CEP 24-Industrial x EMBRAPA 24 & $13,84 \pm 0,14$ & $0,62 \pm 0,14$ & $0,19 \pm 0,48$ & 1 & - \\
\hline EMBRAPA 16x Trigo BR 32 & $13,34 \pm 0,11$ & $-1,34 \pm 0,11$ & $-0,76 \pm 0,28$ & ns & 0,57 \\
\hline EMBRAPA 16 x CEP 24-Industrial & $12,91 \pm 0,15$ & $-0,77 \pm 0,16$ & $1,03 \pm 0,29$ & ns & $-1,34$ \\
\hline EMBRAPA 24 x Trigo BR 23 & $13,46 \pm 0,08$ & $-0,14 \pm 0,08$ & $0,56 \pm 0,19$ & ns & - \\
\hline EMBRAPA 24 x EMBRAPA 16 & $12,53 \pm 0,13$ & $0,67 \pm 0,13$ & $2,43 \pm 0,60$ & 1 & 3,63 \\
\hline
\end{tabular}

${ }^{1}$ Não há graus de liberdade para o teste. 
TABELA 7. Herdabilidade, no sentido amplo, dos caracteres volume de sedimentação, índice de sedimentação e teor de proteína, em nove cruzamentos de trigo. EEA/UFRGS, 1996.

\begin{tabular}{lccc}
\hline Cruzamento & \multicolumn{3}{c}{ Caracteres } \\
\cline { 2 - 4 } & Volume de sedimentação & Índice de sedimentação & Teor de proteína \\
\hline Trigo BR 23 x Trigo BR 32 & 0,47 & 0,59 & 0,20 \\
Trigo BR 23 x EMBRAPA 16 & - & - & 0,29 \\
Trigo BR 32 x CEP 24-Industrial & 0,38 & 0,56 & 0,07 \\
Trigo BR 32 x EMBRAPA 24 & 0,04 & $-0,10$ & 0,52 \\
CEP 24-Industrial x EMBRAPA 24 & 0,22 & 0,64 & 0,30 \\
EMBRAPA 16x Trigo BR 32 & 0,76 & 0,74 & 0,32 \\
EMBRAPA 16 x CEP 24-Industrial & 0,47 & 0,26 & 0,22 \\
EMBRAPA 24 x Trigo BR 23 & 0,47 & 0,48 & 0,26 \\
EMBRAPA 24 x EMBRAPA 16 & 0,72 & 0,54 & 0,44 \\
\hline
\end{tabular}

TABELA 8. Correlações genéticas entre os caracteres volume de sedimentação (VS), índice de sedimentação (IS) e teor de proteína (P) em nove cruzamentos de trigo. EEA/UFRGS, 1996.

\begin{tabular}{lccc}
\hline Cruzamento & VS x IS & VS x P & IS x P \\
\hline Trigo BR 23 x Trigo BR 32 & $1,00^{*}$ & $-0,42^{*}$ & $-0,54 *$ \\
Trigo BR 23 x EMBRAPA 16 & - & - & - \\
Trigo BR 32 x CEP 24-Industrial & $0,76^{*}$ & 0,38 & $-1,02 *$ \\
Trigo BR 32 x EMBRAPA 24 & 0,00 & $1,55^{*}$ & 0,00 \\
CEP 24-Industrial x EMBRAPA 24 & $1,04^{*}$ & $-0,94^{*}$ & $-0,90 *$ \\
EMBRAPA 16x Trigo BR 32 & $0,94^{*}$ & $0,34^{*}$ & $-0,04$ \\
EMBRAPA 16 x CEP 24-Industrial & $0,81^{*}$ & $0,96^{*}$ & 0,06 \\
EMBRAPA 24 x Trigo BR 23 & $0,45^{*}$ & 0,15 & $-0,13$ \\
EMBRAPA 24 x EMBRAPA 16 & $1,04^{*}$ & 0,14 & 0,12 \\
\hline
\end{tabular}

* Significativo a $5 \%$ pelo teste $\mathrm{t}$.

O teor de proteína tem sido apontado como um dos principais fatores que afetam a qualidade de panificação (Pomeranz, 1973); porém, existe interesse em utilizar testes de qualidade que sejam independentes do conteúdo de proteína na farinha, uma vez que este sofre influência marcante do ambiente e apresenta associação negativa com o rendimento de grãos, dificultando a seleção (Gebre-Mariam \& Larter, 1996).

Por meio desses resultados, foi possível observar que, apesar de as correlações elevadas entre volume e índice de sedimentação sugerirem não ha- ver diferença em se utilizar um ou outro como critério de seleção, o primeiro sofreu influência do teor de proteína em relação a um maior número de cruzamentos. Por outro lado, o índice de sedimentação apresenta o inconveniente de exigir a mensuração do teor de proteína em cada amostra. No entanto, na decisão sobre qual dessas medidas indiretas de qualidade utilizar na seleção, é fundamental o conhecimento das correlações entre cada um desses caracteres e a qualidade medida por testes de panificação. A utilização da tecnologia de NIR neste trabalho mostrou ser possível obter estimativas confiáveis quanto a características relacionadas à composição da amostra, como, por exemplo, a proteína total.

Os resultados apresentados neste trabalho são relativos a um ambiente de cultivo, devendo ser considerados dentro desse contexto, porém permitem o delineamento de algumas tendências relativas ao comportamento tanto das cultivares envolvidas quanto dos caracteres analisados. $\mathrm{O}$ índice de sedimentação e o volume de sedimentação têm sua variação genética explicada principalmente por efeitos aditivos. $\mathrm{O}$ estudo das variâncias da geração $\mathrm{F}_{2}$ sugeriu a ocorrência de segregação transgressiva com relação a todos os caracteres analisados, sendo possível obter variabilidade em cruzamentos envolvendo genitores com médias semelhantes, provavelmente, pela existência de genes complementares. O teor de proteína teve influência sobre as medidas de qualidade; porém, por sofrer elevada influência do ambiente, apresenta dificuldade para a seleção. 


\section{CONCLUSÕES}

1. Os caracteres volume de sedimentação e índice de sedimentação são fortemente associados, e sofrem influência do teor de proteína nos grãos.

2. As cultivares CEP 24-Industrial e Trigo BR 23, contribuem com o maior número de genes para o incremento do índice de sedimentação, no conjunto de cruzamentos estudados.

3. A cultivar CEP 24-Industrial, juntamente com Trigo BR 32, contribui com genes para o incremento do teor de proteína.

\section{AGRADECIMENTOS}

A Eliana Maria Guarienti, pesquisadora da Embrapa-Centro Nacional de Pesquisa de Trigo, pelo apoio na realização dos testes de sedimentação; à Importadora e Exportadora de Medidores Polimate Ltda., pela utilização do equipamento para análise de refletância no infravermelho proximal (NIR).

\section{REFERÊNCIAS}

ALLARD, R.W. Principles of plant breeding. 3.ed. New York : J. Wiley, 1960. 485p.

BLACKMAN, J.A.; PAYNE, P.I. Grain quality. In: LUPTON, F.G.H. Wheat breeding: its scientific basis. New York : Chapman and Hall, 1987. p.455-485.

BRUNORI, A.; GALTERIO, G.; ZANNETTINO, C.; POGNA, N.E. Bread-making quality indices in Triticum aestivum progenies: implications in breeding for better bread wheat. Plant Breeding, Berlin, v.102, p.222-231, 1989.

CLARKE, J.M.; HOWES, N.K.; McLEOD, J.G.; DePAUW, R.M. Selection for gluten strength in three durum wheat crosses. Crop Science, Madison, v.33, n.5, p.956-958, 1993.

DEXTER, J.E.; MATSUO, R.R.; KOSMOLAK, F.G.; LEISLE, D.; MARCHYLO, B.A. The suitability of the SDS: sedimentation test for assessing gluten strength in durum wheat. Canadian Journal of Plant Science, Ottawa, v.60, p.25-29, Jan. 1980.

FALCONER, D.S. Introduction to quantitative genetics. 3.ed. Harlow : Longman Harlow Scientific and Technical, 1989. 438p.
GEBRE-MARIAM, H.; LARTER, E.N. Genetic response to index selection for grain yield, kernel weight and per cent protein in four wheat crosses. Plant Breeding, Berlin, v.115, p.459-464, 1996.

GUARIENTI, E.M. Qualidade industrial de trigo. 2.ed. Passo Fundo : Embrapa-CNPT, 1996. 36p. (Embrapa-CNPT. Documentos, 27).

INFRASOFT INTERNATIONAL. NIRS 2 version 3.10: routine operation and calibration development manual. Washington, D.C. : ISI, 1995. 321p.

LORENZO, A.; KRONSTAD, W.E. Reliability of two laboratory techniques to predict bread wheat protein quality in nontraditional growing areas. Crop Science, Madison, v.27, p.247-252, 1987.

MANDARINO, J.M.G. Aspectos importantes para a qualidade do trigo. Londrina : Embrapa-CNPSo, 1993. 32p. (Embrapa-CNPSo. Documentos, 60).

MATHER, K.; JINKS, J.L. Biometrical genetics. 3.ed. London : Chapman and Hall, 1982. 396p.

MOONEN, J.H.E.; SCHEEPSTRA, A.; GRAVELAND, A. Use of the SDS - sedimentation test and SDS - polyacrylamidegel electrophoresis for screening breeder's samples of wheat for breadmaking quality. Euphytica, Dordrecht, v.31, n.2, p.677-690, 1982.

PAYNE, P.I.; CORFIELD, K.G.; BLACKMAN, J.A. Identification of a high-molecular-weight subunit of glutenin whose presence correlates with breadmaking quality in wheats of related pedigree. Theoretical and Applied Genetics, Berlin, v.55, p.153-159, 1979.

PEÑA, R.J.; AMAYA, A. Rapid estimation of gluten quality in bread wheat, durum wheat and triticale using the sodium dodecyl sulfate (SDS) - sedimentation test: grain quality methods. Mexico, DF : International Maize and Wheat Improvement Center, 1985. 12p.

POMERANZ, Y. From wheat to bread: a biochemical study. American Scientist, New Haven, v.61, n.6, p.683-691, 1973.

REUNIÃO DA COMISSÃO SUL-BRASILEIRA DE PESQUISA DE TRIGO, 28., 1996, Passo Fundo. Recomendações. Passo Fundo : Comissão Sul- Brasileira de Pesquisa de Trigo, 1996. 76p.

WRIGLEY, C.W. Developing better strategies to improve grain quality for wheat. Australian Journal of Agricultural Research, Melbourne, v.45, p.1-17, 1994.

Pesq. agropec. bras., Brasília, v.35, n.5, p.975-983, maio 2000 